\title{
Erratum to: Preparation of high-purity phosphatidylcholine from rapeseed oil gums by cation ion-exchange resin
}

\author{
Hui Guo $\cdot$ Yang Yu $\cdot$ Bin Zhang $\cdot$ Junqing Qian
}

Published online: 14 January 2014

(C) Springer-Verlag Berlin Heidelberg 2014

\section{Erratum to: Eur Food Res Technol}

\section{DOI 10.1007/s00217-013-2099-2}

In the original version of the article, caption of Figs. 2, 3, 4, 5 and 6 were incorrectly published. The corrected captions are given below:

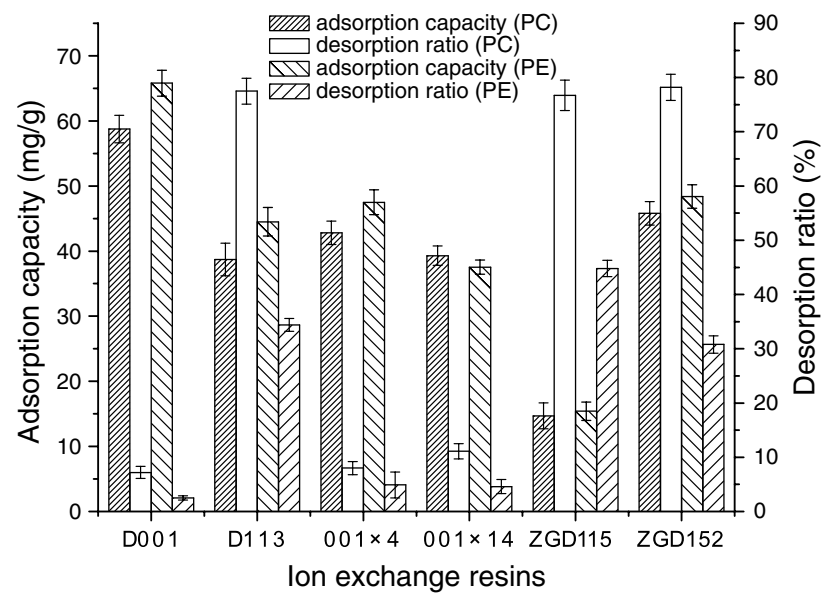

Fig. 2 Adsorption and desorption ratio of PC and PE on different ion exchange resin
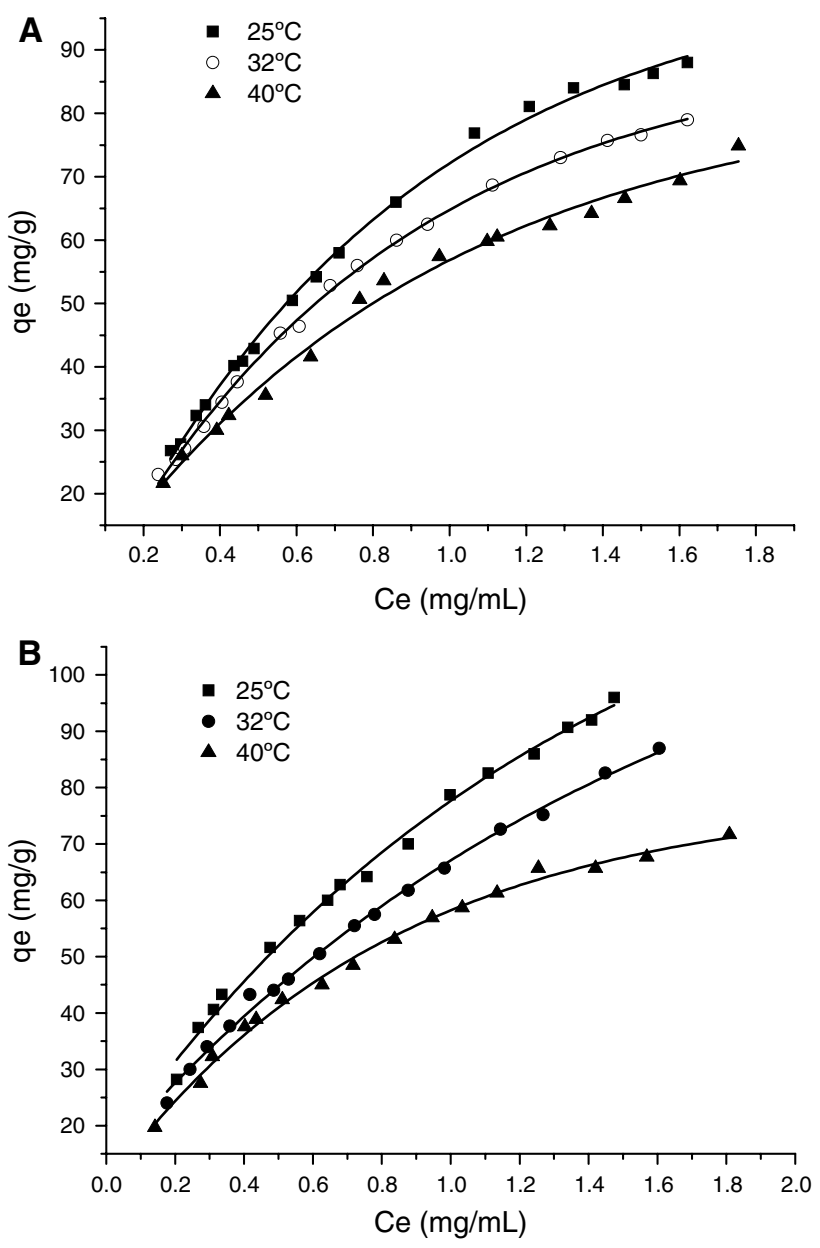

Fig. 3 a Adsorption isotherms for PC on ZGD152 resin at 25, 32 and $40^{\circ} \mathbf{C}$. b Adsorption isotherms for PE on ZGD152 resin at 25, 32 and $40{ }^{\circ} \mathrm{C}$

H. Guo $\cdot$ Y. Yu $\cdot$ B. Zhang $\cdot$ J. Qian $(\bowtie)$

College of Pharmaceutical Science, Zhejiang University

of Technology, Hangzhou 310014, China

e-mail: qianguozjut@163.com 


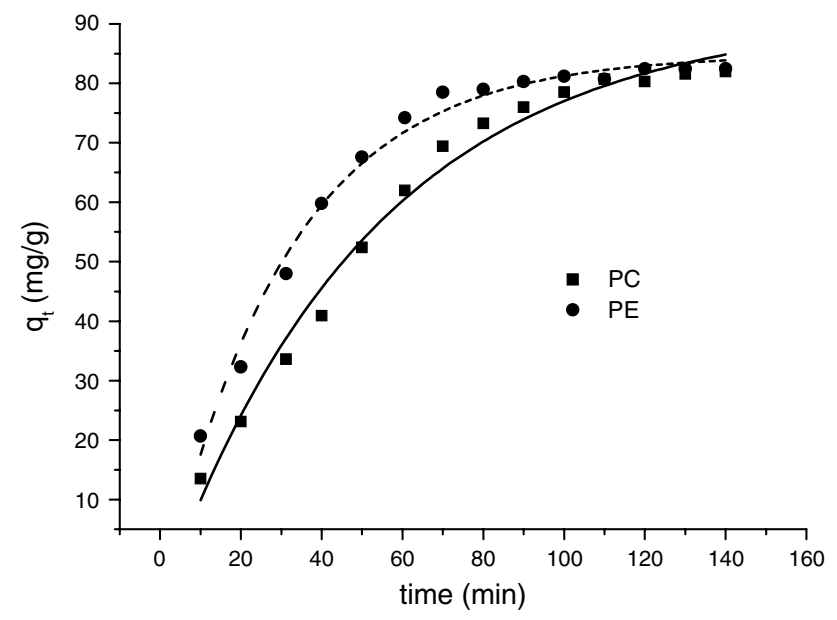

Fig. 4 Adsorption kinetics and diffusion curves for PC and PE on ZGD152 resin at $25^{\circ} \mathrm{C}$

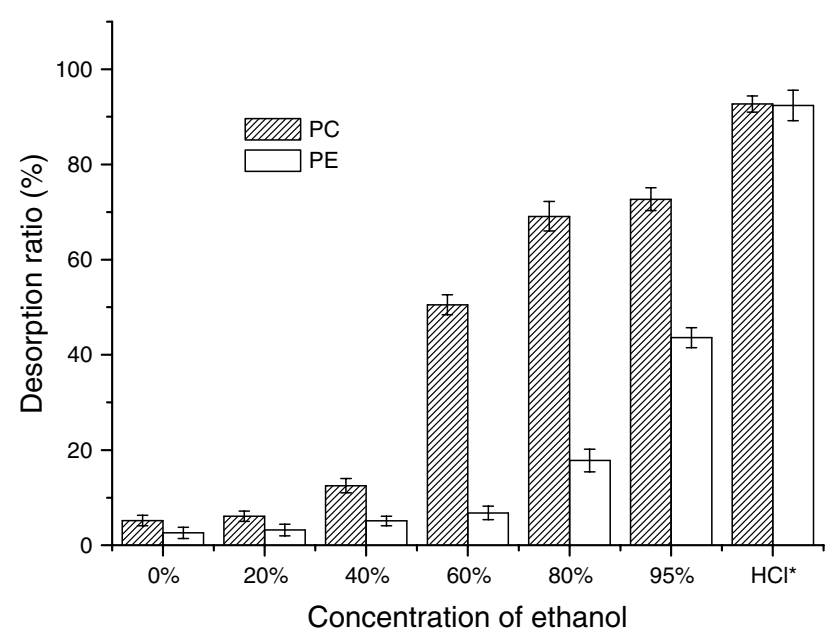

Fig. 5 Static desorption ratio of $P C$ and PE on ZGD152 resin by contacting the different concentration of aqueous ethanol

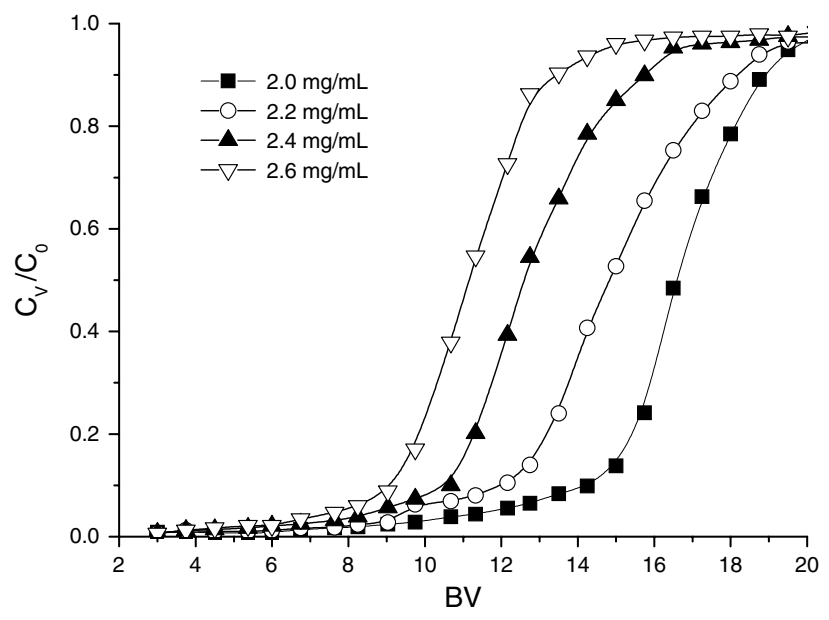

Fig. 6 Effect of initial PC concentration on breakthrough at bed volume of $108.0 \mathrm{ml}, 25^{\circ} \mathrm{C}$, flow rate at $0.008 \mathrm{BV} / \mathrm{min}$ 